\title{
EIGHT-WEEK SET-PIECES AND DOUBLE-TEAMING TRAINING ON SCORING PRECISION OF UNIVERSITY OF IBADAN FOOTBALL PLAYERS, IBADAN, NIGERIA
}

\author{
Festus A. Adegoju ${ }^{i}$ \\ Exercise Physiology Unit, \\ Department of Human Kinetics, \\ Faculty of Education, \\ University of Ibadan, \\ Ibadan, Nigeria
}

\begin{abstract}
:
This study sought to investigate the effect of eight-week set-pieces and double-teaming training on scoring precision of the University of Ibadan football players. The proposed sample size for this study was twenty one football players of the University of Ibadan. All the participants completed the intervention programme. Randomised pretest-posttest experimental research design of $3 \times 2 \times 3$ factorial matrix was used for the study. Descriptive statistics of frequency counts and percentages was used to analyse the demographic data and research questions while inferential statistics of Analysis of Covariance (ANCOVA) was used to test hypotheses at 0.05 level of significance. Two research questions were answered while seven hypotheses were tested. Findings from this study revealed that there was a significant main effect of treatment on scoring precision of the football players. $(F=65.120, p<.05, \eta 2=.963)$. The eta value of 0.963 showed that $96.3 \%$ of the variance in the participant's score was accounted for by the intervention. It was also observed that there was a variance of 87.5 percent accounted for by the independent variables combined together. There was no significant main effect of playing position on scoring precision. Likewise, there was no significant main effect of playing experience on scoring precision. The interaction effect of the two moderating variables was not significant. The study also concluded that the interaction effect of treatment, playing position and playing experience has no significant effect on scoring precision of the University of Ibadan players. Based on the findings of this study, it was concluded that the treatment was effective on scoring precision among football players. However, it was noted that double-teaming was better on scoring precision than set-pieces.
\end{abstract}

Keywords: set pieces, double-teaming, scoring precision, precision board, dummy

i Correspondence: email festosnap@gmail.com 


\section{Introduction}

Football is a sport played between two teams of at least, seven and at most, eleven players with a spherical ball. The main objective of this game is to score goals. Therefore, the concept of scoring precision is a major factor that must be taken seriously because it is the architect of the objective of football game. Due to its increasing popularity, as well as the amount of financial interest in the game, football is the world's most popular sport. The game is played on a rectangular field with a goal post at each end. The objective of the game is to score goals by moving the ball completely beyond the goal line between the goal posts and under the crossbar. Number of games won due to number of goals scored and the number of goals conceded is what differentiates one team from the other on the competition table. The ability to execute skilled movement patterns efficiently and effectively to score goals into the opposing goal is about the most important aspect of football performance. Football players must apply certain skills, techniques, and tactics to execute goal scoring precision. Football involves majorly three types of skills viz: tactical, technical and goal scoring precision.

Scoring precision is the ability to aim, shoot and score goals consistently in football. The learned and sustained ability to bring about pre-determined results with maximum certainty in goal scoring can also be referred to as scoring precision. Dukic (2000), states that the potential for scoring precision has become not only a strategy for teams but also for team success in competitions. For instance, in a sample of 202 goals from 109 football matches in the 2016 European Premiership League, (Hughes, 2012) found that 92 goals were scored from set plays and double-teaming or immediately from regained possession following a clearance from set plays and double-teaming. Precision in football depends on goal scoring skill acquisition through repeated and consistent training, center for perception and its connection with the reticular system and sensitive motor coordination (Maric, 2003). It is the state or degree of being exact in the quality of having high accuracy and consistency in scoring goals in football. Scoring precision is also the quality of being reproducible in amount of products delivered in repeated performance in football game (Nićin, 2000).

Set-pieces are skills used from balls out of touch from the attacking third of the field to score goal. Any type of free kicks (direct or indirect), goal kick, corner kick, kickoff, penalty kick, throw-in or dropped balls are considered as set pieces. Other phrases or words used to describe these situations are "Dead-Balls" and "Re-Starts". When a foul is committed or there is an infringement of the law of the game or ball goes out of play during a match, the referees employ specific methods of putting the game back into play

Stojiljkovic (2003) reveals that the methods of putting the game back in progress are referred to as set-pieces. A set-piece is the time a ball is stationary and opportunity is given to the attacking team to actually organise and run a set play of sorts where the opponent must give enough space for the attacking team to restart the game. Fantasy Football Tips (2012) refers to set piece as a situation when the ball is returned to open 
play, for example, following a stoppage, particularly in a forward area of the pitch. This skill may occur in any part of the field, but set-pieces are emphasised upon more when it is closer to the opponent's goal especially at the attacking third of the field.

Double-teaming is an attacking strategy where two attackers tend to bypass defenders where one of the attackers forms a dummy to confuse the players of the defending team to score goals. Adegoju and Abon (2020)) reveal that double teaming was commonly used in the defense but recent development in the game of football prompts the use of double-teaming as an attacking tactical tool in recent times. Making an offensive line to work together is the most vital part to the success of an offensive play in double-teaming. From penetrating pass in possession to picking up a double-team mate, the player initiating the double-team attack must be ready to help his fellow team mate (The Soccer Guide, 2010). Brad (2014) states that one key fundamental skill which should be taught and acquired in football is the double teaming. This can be done between the center, left side and right side of the attacking third of the field. He states further that the duo and the assistant who are performing the double-teaming role must not be far apart for more efficiency.

\section{Statement of the Problem}

The primary objective of competitive football game is for a team to score more goals than the opponent. Therefore, each and every player in a team should have the knowledge, ability and acquire the skill of goal scoring. However, many teams do not devote the necessary time and practice in training to improve their set-plays and double- teaming in the developing world. The University of Ibadan football team is one of the teams that do not score well from set pieces and double-teaming. The 2011 Nigeria University Games (NUGA), hosted by University of Benin was the last the University of Ibadan football team participated in. The team played five matches in all. She scored the total of three (3) goals and conceded eight (8). None of these goals came from set-pieces or doubleteaming. Also, at the 2017 Ibadan Football Association (IFA) League 2017 season, University of Ibadan football team played eighteen (18) matches, five (5) goals were scored and conceded sixteen (16). Only one (1) goal was scored from set piece (penalty) but none from double-teaming despite the fact that chances of converting set pieces and double-teaming into goals through precision arose severally during the games. They, however, were not converted into goals. Therefore, making very good use of scoring chances from set plays and double-teaming cannot be over emphasized. This is especially important as these situations arise regularly throughout matches and it is very important to improve the prospects of making the most of them in order to do well in competitions. Several studies have been done on University of Ibadan football players. Adegoju and Abon (2020) worked on effects of Double-Teaming and Three-Man Weave Training on Goal-Scoring accuracy among players of Federal University of Agriculture Football Team, Abeokuta, Ogun State, Nigeria, while Owoeye, Akinbo, Olawale, Tella and Ibeabuchi (2013) focused on injury prevention on the players in this team. But little 
research effort has been directed towards scoring precision. It is in light of this that this study intends to determine the effects of eight weeks set pieces and double-teaming training on scoring precision of University of Ibadan Football players. The main objective of the study is to examine the effects of set pieces and double- teaming training on scoring precision of University of Ibadan football players.

\subsection{Research questions}

The study provided answers to the following questions:

1) Will set pieces lead to scoring more goals during University of Ibadan football team matches?

2) Will University of Ibadan football players prefer the use of double-teaming to set pieces in game situations?

\subsection{Hypotheses}

The following hypotheses were tested in the study

1) There will be no significant main effect of treatments on scoring precision of University of Ibadan football players.

2) There will be no significant main effect of playing experience on scoring precision of University of Ibadan football players.

3) There will be no significant main effect of playing position on scoring precision of University of Ibadan football players.

4) There will be no significant interaction effect of treatments and playing experience on scoring precision of University of Ibadan football players.

5) There will be no significant interaction effect of treatment and playing position on scoring precision of University of Ibadan football players.

6) There will be no significant interaction effect of playing experience and playing position on scoring precision of University of Ibadan football players.

7) There will be no significant 3-way interaction effect of treatment, playing experience and playing position on scoring precision of University of Ibadan football players.

\section{Methodology}

Randomised pretest-posttest/control experimental research design of 3X3X2 factorial matrix was used for this study. Descriptive statistics of frequency counts and percentages was used to analyse the demographic data and research questions while inferential statistics of Analysis of Covariance (ANCOVA) was used to test hypotheses at 0.05 level of significance. Two research questions were answered while seven hypotheses were tested.

The population for this study was all University of Ibadan football players, University of Ibadan, Nigeria. Twenty one (21) football players of the University of Ibadan were recruited for this study as participants. All the participants successfully 
completed the 8-week training without an attrition. Total sampling technique was used to recruit the participants. Simple random sampling technique was used to assign the participants into three (3) groups of seven (7) participants in each. Experimental group (1) one was for set pieces training, experimental group (2) two undergone doubleteaming training while group (3) was the control group which undertook convectional training. Pretest assessment was done at the initial stage of the intervention while Posttest assessment was also done after intervention had been concluded.

\subsection{Research instruments}

The following research instruments were used for data collection;

1. Standard football pitch: Football field was used to carry out training

2. Cones of various sizes: they were used for organisation of surface area for each training and test.

3. Landmarks: these pieces of equipment were used for metric demarcations during training and tests.

4. Whistle: this was used to draw attention of players to moderations when to start and when to stop during intervention and tests.

5. Stop Watch: this was used to time participants during intervention and tests.

6. Measuring tape: a calibrated in meter measuring tape used for taking necessary distance measurements.

7. Scoring sheets and pen: scoring sheets were used to record scores of tests of participants while pen was used to write values scored into the scoring sheets.

8. Protractor: this is necessary for measuring angles of players' contact on the ball.

9. Football cases: they were used by the players to train and to take pretest and posttest values.

10. Jerseys: four different sets of these were worn on by the players. One colour for set pieces team, another for double-teaming team, the third for the control group while the last one was for the researcher and the research assistants majorly worn for identification purpose.

11. Playing boots: these were worn by the players for training and tests

12. Canvas: these were worn for warm up exercises by the players and also worn by the researcher and the research assistants.

13. Goal post: a standard football goal post 7.32meters X 2.44 meters was used.

14. Ball Board: this is an abridged prototype of the football field with players in it. It was used to rehearse in the class what the players did on the field when tests and training began.

15. Short hurdles: they were used for players' warm up sessions.

16. 2.0 meters X 2.2 meters Canvas board (Precision board): this was hung on the football goal crossbar as target to measure free kick for scoring precision. 


\subsection{Test Location}

The location of this study was the New Stadium Football Pitch near Obafemi Awolowo Hall, University of Ibadan, Nigeria.

\subsection{Procedure for Training Programme and Data Collection}

A letter of introduction was collected from the Head of Department of Human Kinetics and Health Education, University of Ibadan for the purpose of identification. The consent of the Director of Sport, University of Ibadan and the head coach of the football team and the participants was duly sought to elicit their willingness to cooperate with the researcher. The purpose of the study and the possible risks involved in the tests was explained to the participants. All the participants signed and submitted the informed consent form and were allowed to participate in the study.

\subsection{Test Protocol}

Set pieces tests: three (3) variables were tested under set pieces. They include:

- penalty kick,

- corner kick, and

- free kick.

\subsection{Penalty Kick Skilled Test}

Objective: to test skill and scoring precision of players from the penalty kick.

Equipment: cones, balls, landmarks, jerseys, playing boots, whistle and the goal post were used for this test.

Procedure: after a thorough warm up exercise, the ball was placed on the penalty mark 11 meters away from the goal line within the penalty area. The player kicks the ball forward towards the goal after the blast of the whistle by the research assistant. No guarding of the goal is important for this test. Ten trials make up the test.

Scoring: if the ball enters the goal mouth on the fly to any far side up within the goal post, 5 points are awarded. But if it enters any of the far sides of the goal post on the bounce or in the middle 4 points are awarded; on the roll and low, 3 points, if it scores at the roof in the center, 2 points, if it touches the upright or the bar and enters anywhere 1 point is awarded. No point is awarded if the ball enters the center of the goal post where the goal keeper assumedly stands. No point is also given if a goal is not made. The total numbers of points made on the ten kicks were recorded.

\section{Fouls:}

- kicking the ball from any spot other that the penalty mark,

- kicking the ball when it is not stationary,

- kicking the ball more than once on a trial,

- kicking the ball before the whistle.

The procedure of McDonald Soccer Precision Tests, cited by Miller (2002) was adopted for this study. 
Figure 1: Penalty Kick Training, Test and Scoring method

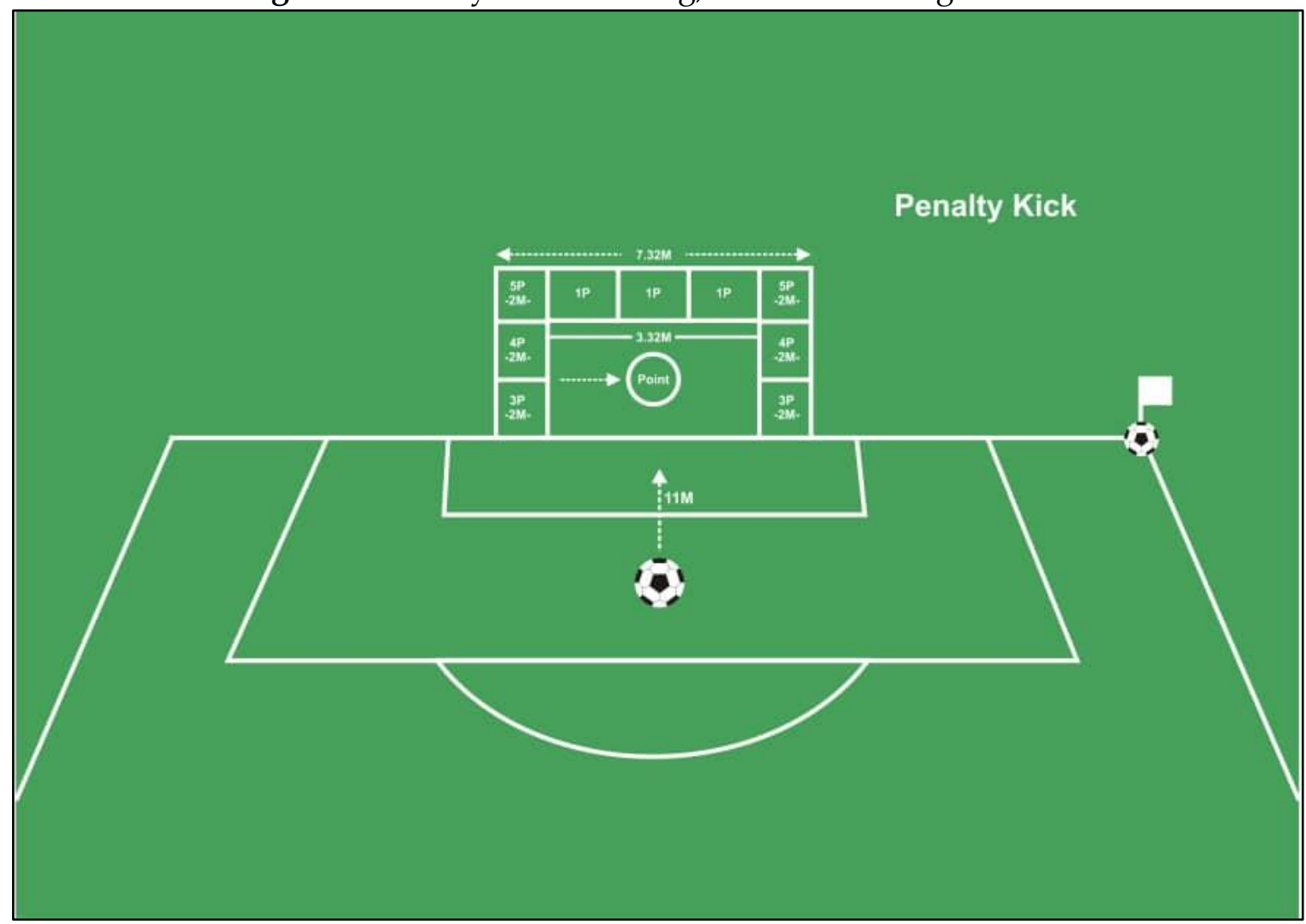

\subsection{The Corner Kick Skilled Test}

Objective: to test skill and scoring precision of players from the corner kick.

Equipment: a marked 5 meters square inside the penalty area, clearly marked corner kick arc at both ends of the goal line, ball, cones, jerseys, playing boots, landmarks, whistle and the goal post were used for this test.

Procedure: place the ball within one meter corner arc and kick towards the goal. The ball was expected to land within the designated 5 meter square on the penalty area.

Scoring: ten attempts were allowed for each participant. If the ball lands directly from the corner kick on the fly onto the center of the 5 meter square, 5 points are awarded. If the ball lands in any way other than a fly onto the center of the designated square, 4 points are awarded. If the ball hits the goal post and bounces off it to land on the center of the square, 3 points are awarded. If the ball hits the cross bar and hits the center of the square, 2 points are awarded. If the ball hits either the upright or the crossbar and hits any part of the square, 1 mark is awarded. If the kick does not touch any part of the square in anyway, no point is awarded. No points are also awarded if fouls occur. The total number of points made out of the attempts from ten kicks was recorded.

Foul: violation of all football rules on corner kick.

The procedure of McDonald Soccer Precision Tests, cited by Miller (2002) was adopted for this study. 
Figure 2: Corner Kick Training, Test and Scoring method

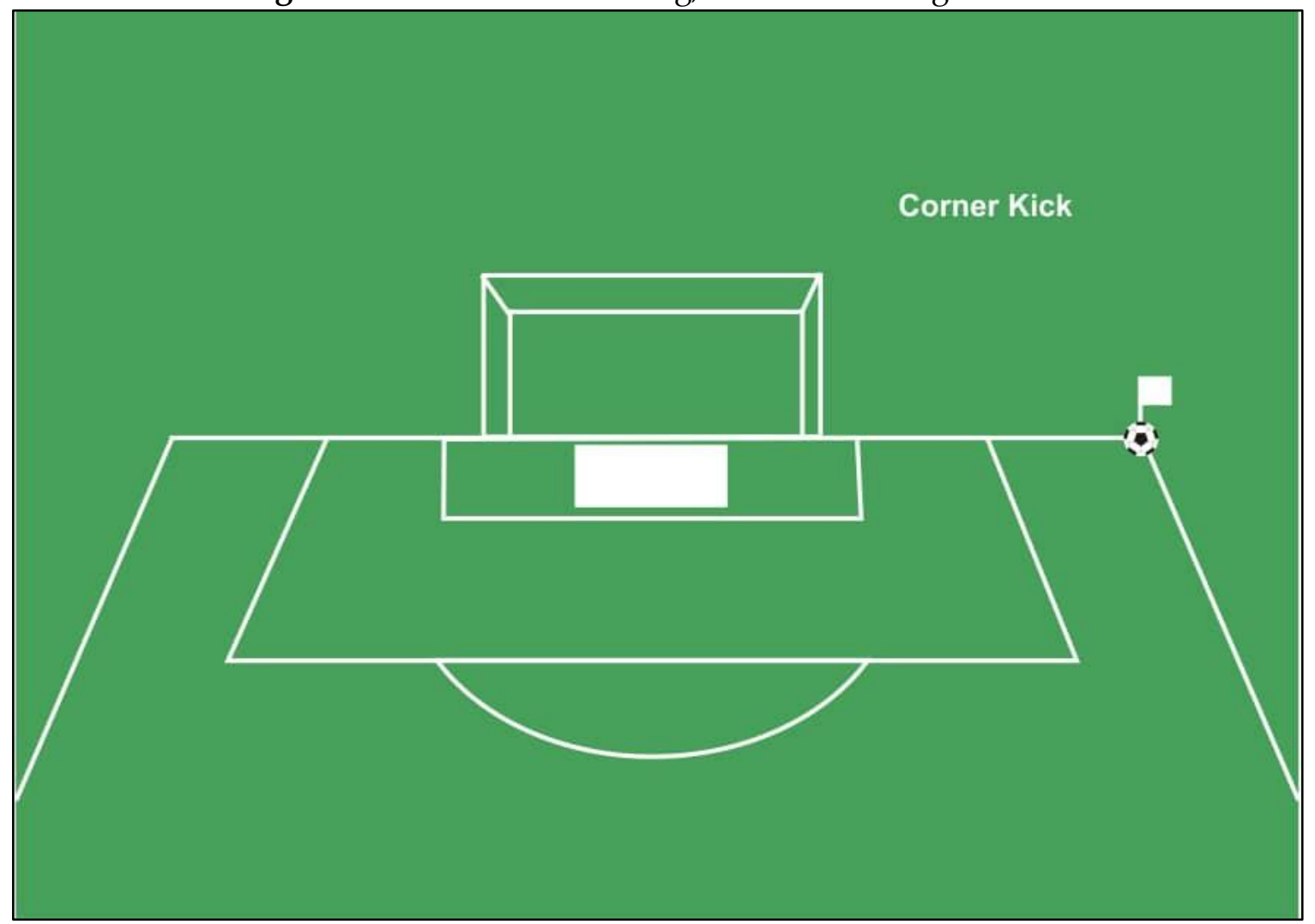

\subsection{Free kick skilled test}

Objective: to test skill and scoring precision of players from the free kick.

Equipment: a painted target of 2.0meters by 2.2 meters (Precision Board), cones, landmarks, whistle, ball, jerseys, playing boots, and the goal post were used for this test. Procedure: a target is painted on a 2.0 meters by 2.2 meters canvas which was hung from the cross bar of the goal post. The center measured 0.5 meters in diameter, the middle was 0.9 meters while next to it was 1.2 meters and the outer circle was 1.8 meters in diameter. The bottom lay flat from the ground. It was recommended that a wooden or metal bar be indented in a channel sewn along the bottom of the canvas, and then the channel be fastened to the goal posts to keep the canvas stretched taut. A restraining line is demarcated with the landmarks 18 meters from the target. The player takes few running steps towards the restraining demarcation and then shoots the ball placed on the restraining line to hit the canvas target. Ten attempts were allowed for this test.

Scoring: if the ball hits the center, 5 points is awarded. If it hits the next rectangle on the precision board, 4 points, the next rectangle wins 3 points, the next 2 points and the outermost rectangle wins 1 point. If the ball hits the line demarcating the rectangles, the higher point is awarded. If the ball does not hit the target, no point is awarded. No point is also awarded if any foul is committed. The total numbers of points made on the ten kicks were recorded.

Foul: violation of all football rules on free kick. 
The procedure of McDonald Soccer Precision Tests, cited by Miller (2002) was adopted for this study.

Figure 3: Free kicks Training, Tests and Scoring method

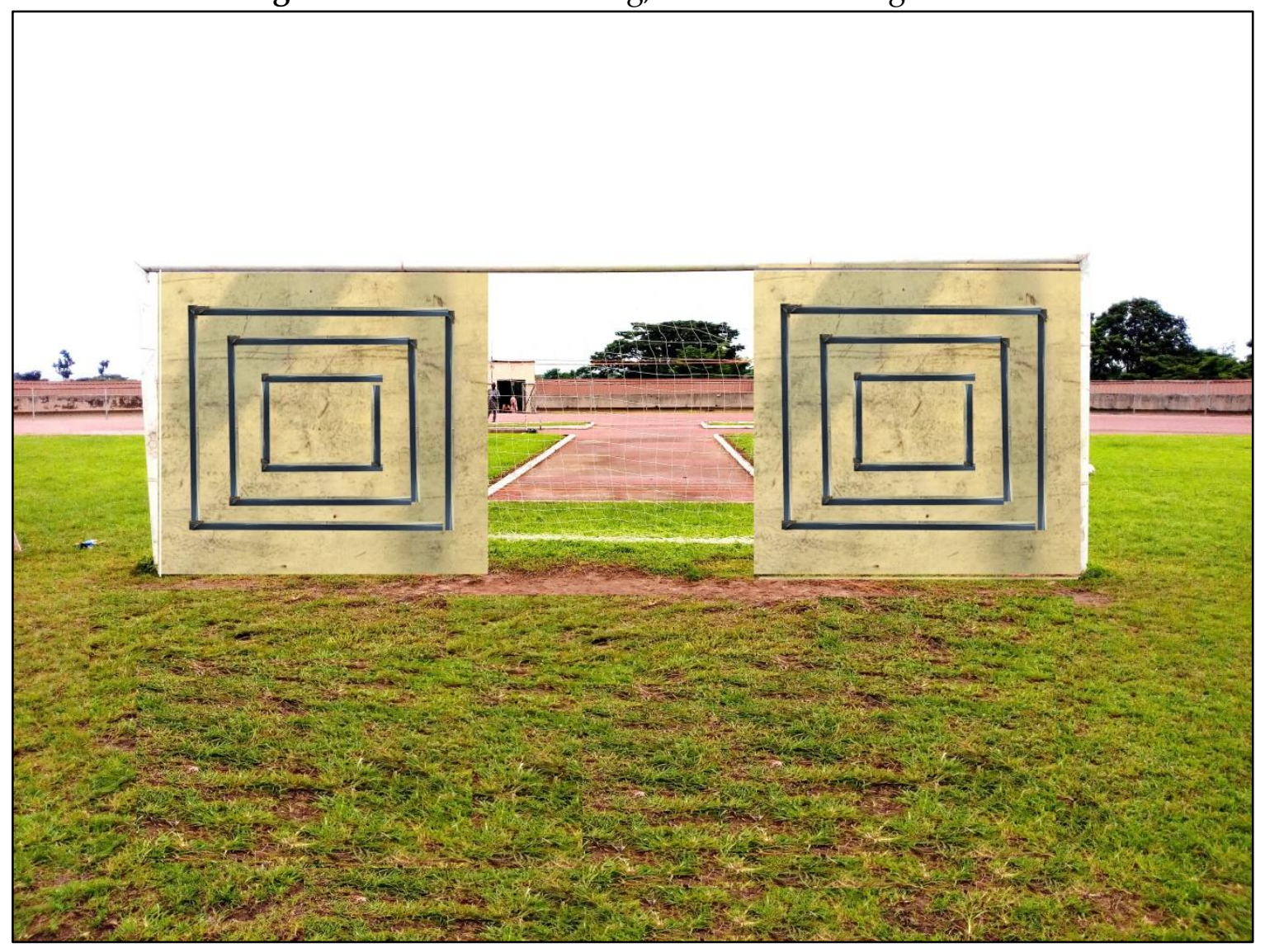

\subsection{Double-Teaming Skilled Test}

Objective: to test skill and scoring precision of players from double-teaming.

Equipment: cones, balls, landmarks, jerseys, playing boots, whistle and the goal post were used for this test.

Procedure: players were made to warm up satisfactorily. After the blast of the whistle by the research assistant, an attacking player $\mathbf{Q}$ picks the ball at a designated point $\mathbf{A}, 30$ meters away from the goal line and approaches the goal with the ball as quickly as possible with the second player $\mathbf{R}$ running perpendicularly with him to meet at a point $\mathbf{B}$ 20 meters away from goal line to form a dummy. Momentarily as they meet, the second attacking player $\mathbf{R}$ dashes away from player $\mathbf{Q}$ unto the open field about 5 meters away. At that point, player $\mathbf{Q}$ passes the ball very fast to player $\mathbf{R}$ who without trapping shoots the ball to either the left or right side of the goal post.

Scoring: goals scored at the top left or right far corner of the post about 2 meters from the upright is assigned 5 points, middle left or right 2 meters from the upright is assigned 4 points, the ground left or right far corner is assigned 3 points while any goal scored in the middle upper center above (roof) is assigned 2 points. If it touches the bar or upright and scores in any part of the goal post, it is assigned 1 point. Any goal scored at the center 
of the goal post, or did not enter into the goal post, or hits the cross bar or upright and goes out is assigned 0 point. These scoring positions shall be demarcated and explained to all the participants before the commencement of the test. Each of the seven participants takes turn to play with any of the other players assisting. Participant $\mathbf{R}$ is measured. Ten trials are allowed for each participant. The total numbers of points made on the ten kicks were recorded. This test was administered at the right, left and center zones of the field.

\section{Fouls:}

- starting the test without waiting for the whistle,

- running wider, farther or shorter off the marked perimeters,

- trapping the ball before final kick towards the goal.

The procedure of McDonald Soccer Precision Tests, cited by Miller (2002) was adopted for this study.

Figure 4: Double-teaming Training, Test and Scoring method

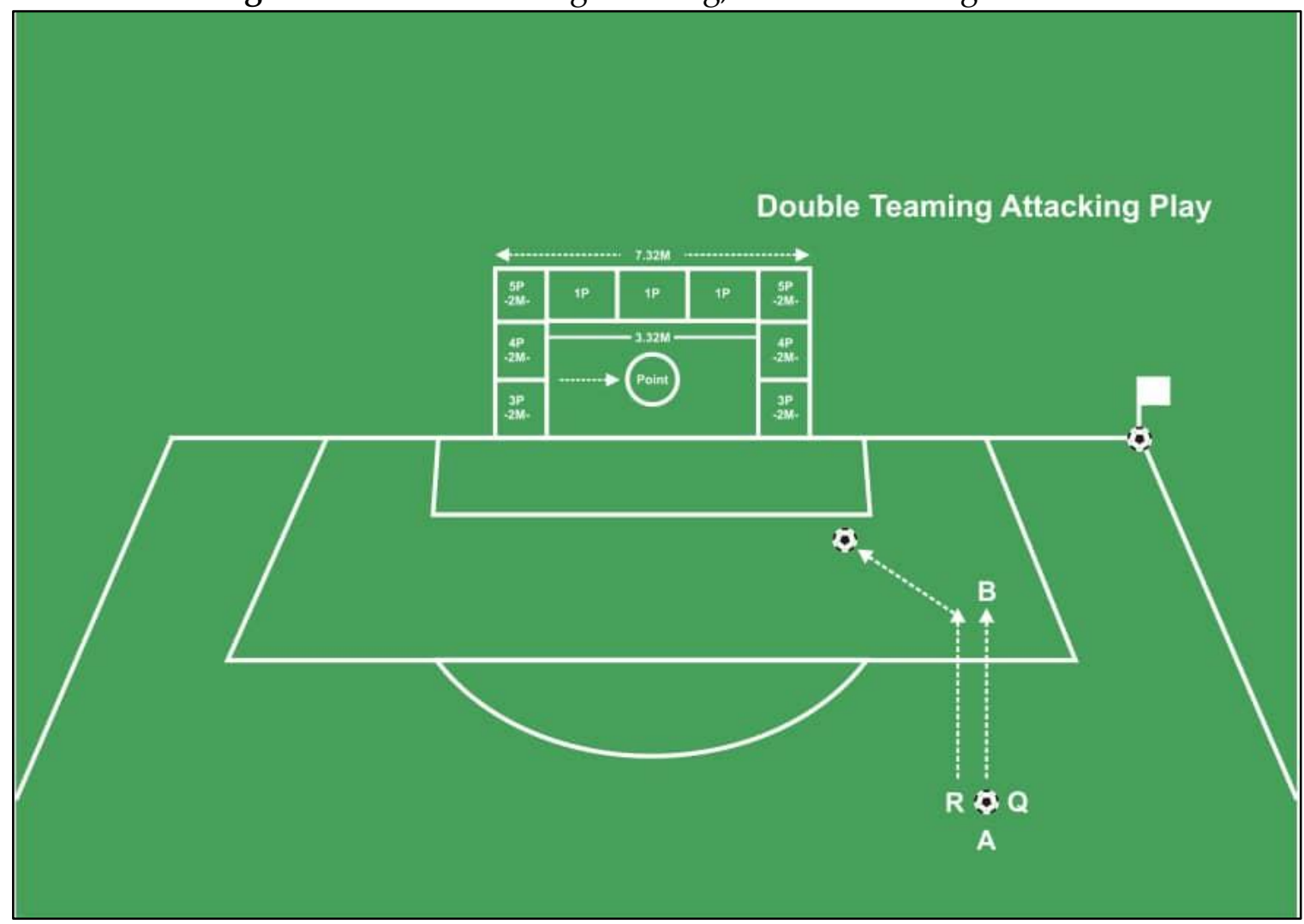

\subsection{Procedure for Data Analysis}

Descriptive statistics of frequency counts and percentages was used to analyse the demographic data and research questions while inferential statistics of Analysis of Covariance (ANCOVA) was used to test hypotheses at 0.05 level of significance. 


\section{Results and Discussions}

This following are the results of the research questions and hypotheses:

Table 1: Summary of Participants' Demographic Profile

\begin{tabular}{|l|l|c|c|}
\hline Demographic Characteristics & Frequency & Percentages \% \\
\hline Playing position & Defence & 6 & 28.6 \\
& Midfield & 9 & 42.9 \\
& Forward & 6 & 28.6 \\
\hline Playing experience & Short $(0-2$ years $)$ & 13 & 61.9 \\
& Long (2-4 years) & 8 & 38.1 \\
\hline Treatment & Double teaming & 7 & 33.3 \\
& Set piece & 7 & 33.3 \\
& Control & 7 & 33.3 \\
\hline
\end{tabular}

Table 1 shows that $6(28.6 \%)$ of the players were Defenders, 9(42.9\%) were Midfielders and $6(28.6 \%)$ played in the forward position. $13(61.9 \%)$ had short playing experience while $8(38.1 \%)$ had long playing experience. $7(33.3 \%)$ were in the Double teaming group, $7(33.3 \%)$ were in the Set piece group and 7(33.3\%) were in the Control group.

Hypothesis one: There will be no significant main effect of treatments on scoring precision of University of Ibadan football players.

Table 2: Pretest/post-test of double-teaming group, set pieces group and control group $(n=21)$

\begin{tabular}{|l|l|l|c|}
\hline \multicolumn{2}{|c|}{ Pretest raw data (\%) } & \multicolumn{2}{c|}{ Post-test raw data (\%) } \\
\hline Double-teaming & $17.9 \%$ & Double-Teaming & $56.7 \%$ \\
\hline Set pieces & $16.9 \%$ & Set pieces & $55.7 \%$ \\
\hline Control & $0.18 \%$ & Control & $0.20 \%$ \\
\hline
\end{tabular}

Table 3: Estimated marginal means of treatments on Scoring Precision of University of Ibadan football players

\begin{tabular}{|l|c|c|c|c|}
\hline \multirow{2}{*}{ Treatment Groups } & \multirow{2}{*}{$\mathbf{x}$} & \multirow{2}{*}{ Std. Error } & \multicolumn{2}{|c|}{$\mathbf{9 5 \%}$ Confidence Interval } \\
\cline { 4 - 5 } & & & Lower Bound & Upper Bound \\
\hline Double Teaming & 8.042 & .384 & 7.055 & 9.030 \\
Set Piece & 7.768 & .395 & 6.754 & 8.782 \\
Control & 2.646 & .385 & 1.656 & 3.637 \\
\hline
\end{tabular}

Table 3 showed the estimated marginal means of treatment on scoring precision. Participants in double-teaming group had the highest mean $(\overline{\mathbf{x}}=8.042)$, followed by participants in set piece group with a mean of $(\overline{\mathbf{x}}=7.768)$. Participants in control group had the least mean score of $(\overline{\mathbf{x}}=2.646)$. This showed that participants in double teaming performed better in scoring precision than the participants in set piece and control. Overall comparison showed that participants in double-teaming group were the best in scoring precision followed by those in set pieces and control. Findings therefore revealed that there was a significant main effect of treatment on scoring precision of University of 
Ibadan football players. ( $F=65.120, p<.05, \eta 2=.963$ ). Thus, the null hypothesis is rejected. The eta value of .963 showed that $96.3 \%$ of the variance in the participant's score was accounted for by the intervention. This is line with Bobavonic (2010) who opined that double-teaming can certainly be one attacker putting pressure on a defender while the other attacker forms a dummy on the defender in the form of distraction in order to bypass him with the ball to score goals readily.

Table 4: Post Hoc Test showing multiple pair-wise analyses of Treatment on Scoring Precision

\begin{tabular}{|l|l|c|c|c|}
\hline (I) Treatment & (J) Treatment & $\begin{array}{c}\text { Mean Difference } \\
\text { (I-J) (J-I) }\end{array}$ & $\begin{array}{c}\text { Std. } \\
\text { Error }\end{array}$ & $\begin{array}{c}\text { Sig. } \\
\text { p-value }\end{array}$ \\
\hline Double-teaming & Set pieces & .1429 & .4056 & .940 \\
& Control & $5.4857^{*}$ & .4056 & .000 \\
\hline Set pieces & Double teaming & -.1429 & .4056 & .940 \\
& Control & $5.3429^{*}$ & .4056 & .000 \\
\hline Control & Double teaming & $-5.4857^{*}$ & .4056 & .000 \\
& Set pieces & $-5.3429^{*}$ & .4056 & .000 \\
\hline
\end{tabular}

${ }^{*}$ sig. at .05 level.

Table 4 shows that there were pair-wise significant differences between double-teaming and control group, set pieces and control group. This table explains the mean difference (I-J) between the first treatment (I) double-teaming and second treatment (J) (set pieces) on scoring precision of the football players. It was revealed that [(I) minus $(\mathrm{J})]$ value of .1429 shows $14.29 \%$ mean difference. This means that the difference between the mean of double-teaming and set pieces on scoring precision is $14.29 \%$ while the mean difference between set pieces $(\mathrm{J})$ and double-teaming $(\mathrm{I})[(\mathrm{J}-\mathrm{I})]$ on scoring precision is -.1429 which shows $-14.29 \%$. while mean difference value between control of double-teaming is -5.4857 which showed $-54.85 \%$. The mean difference value between control and set pieces is 5.3429 which shows $-54.42 \%$.

Hypothesis two: There will be no significant main effect of Playing Position on Scoring Precision of University of Ibadan football players.

Table 5: Estimated marginal means of Playing Position on Scoring Precision of University of Ibadan football players

\begin{tabular}{|l|c|c|c|c|}
\hline \multirow{2}{*}{ Playing Position } & $\overline{\mathbf{x}}$ & \multirow{2}{*}{\begin{tabular}{c} 
Std. \\
\cline { 3 - 4 }
\end{tabular}} & Error & \multicolumn{2}{|c|}{$\mathbf{9 5 \%}$ Confidence Interval } \\
\cline { 4 - 5 } & & .423 & $40 w e r$ Bound & Upper Bound \\
\hline Defence & 5.803 & .343 & 5.717 & 6.890 \\
Midfield & 6.307 & .433 & 5.245 & 7.188 \\
Forward & 6.356 & & 7.469 \\
\hline
\end{tabular}

Table 5 shows the estimated marginal means of Playing Position on Scoring Precision of University of Ibadan football players. Although, playing position was not significant in enhancing scoring precision, however, attacking players had the highest mean $(\overline{\mathbf{x}}=6.356)$, followed by participants in midfield players with a mean value of $(\overline{\mathbf{x}}=6.307)$. Participants in defence position had the least mean score of $(\overline{\mathbf{x}}=5.803)$. This shows that participants 
in forward performed better in scoring precision than the midfield players. Overall comparison shows that participants in forward position were better in scoring precision followed by those in midfield and defence. Therefore, there is no significant main effect of Playing Position on Scoring Precision of University of Ibadan football players. $(\mathrm{F}=.310$, $\left.\mathrm{p}>.05, \eta^{2}=.110\right)$. Thus, the null hypothesis is accepted. The eta value of .110 showed that $11 \%$ of the variance in the participant's score was accounted for by the intervention.

Hypothesis three: There will be no significant main effect of Playing Experience on Scoring Precision of University of Ibadan football players.

Table 6: Showing Estimated Marginal Mean of

Playing Experience on Scoring Precision of University of Ibadan football players

\begin{tabular}{|l|c|c|c|c|}
\hline \multirow{2}{*}{ Playing Experience } & \multirow{\mathbf{x}}{*}{$\begin{array}{c}\text { Std. } \\
\text { Error }\end{array}$} & \multicolumn{2}{|c|}{ 95\% Confidence Interval } \\
\cline { 4 - 5 } & & Lower Bound & Upper Bound \\
\hline Short Playing Experience & 6.281 & .291 & 5.533 & 7.028 \\
\hline Long Playing Experience & 5.960 & .359 & 5.036 & 6.883 \\
\hline
\end{tabular}

Table 6 shows the estimated marginal means of Playing Experience on Scoring Precision of University of Ibadan football players. Although, playing experience was not significant in enhancing scoring precision, however, participants with short playing experience had the higher mean $(\overline{\mathbf{x}}=6.281)$ followed by participants with long playing experience having a mean of $(\overline{\mathbf{x}}=5.960)$. This showed that participants with short playing experience performed better in scoring precision than the participants with long playing experience. Therefore, there was no significant main effect of Playing Experience on Scoring Precision of University of Ibadan football players. ( $\left.F=.138, p>.05, \eta^{2}=.027\right)$. Thus, the null hypothesis is accepted. The eta value of .027 showed that $27 \%$ of the variance in the participant's score was accounted for by the intervention.

Hypothesis four: There will be no significant interaction effect of Treatment and Playing Position on Scoring Precision of University of Ibadan football players.

Table 7: Estimated marginal means of Treatment and

Playing Position on Scoring Precision of University of Ibadan football players

\begin{tabular}{|c|c|c|c|c|c|}
\hline \multirow{2}{*}{ Treatment } & \multirow{2}{*}{ Playing Position } & \multirow{2}{*}{$\overline{\mathbf{x}}$} & \multirow{2}{*}{$\begin{array}{l}\text { Std. } \\
\text { Error }\end{array}$} & \multicolumn{2}{|c|}{ 95\% Confidence Interval } \\
\hline & & & & Lower Bound & Upper Bound \\
\hline \multirow[t]{3}{*}{ Double-teaming } & Defence & 7.903 & .681 & 6.152 & 9.654 \\
\hline & Midfield & 7.846 & .588 & 6.334 & 9.358 \\
\hline & Forward & 8.713 & .684 & 6.954 & 10.472 \\
\hline \multirow[t]{3}{*}{ Set pieces } & Defence & 8.553 & .681 & 6.802 & 10.304 \\
\hline & Midfield & 8.181 & .657 & 6.493 & 9.869 \\
\hline & Forward & 6.963 & .684 & 5.504 & 8.722 \\
\hline \multirow[t]{3}{*}{ Control } & Defence & 2.329 & .702 & .525 & 4.133 \\
\hline & Midfield & 2.893 & .613 & 1.316 & 4.470 \\
\hline & Forward & 2.786 & .708 & .965 & 4.608 \\
\hline
\end{tabular}


Table 7 shows the estimated marginal means of Treatment and Playing Position on Scoring Precision of the players. Although, the interaction of the treatment and playing position was not significant in enhancing scoring precision, however, attacking players who are in double-teaming group had the highest mean value of $(\overline{\mathbf{x}}=8.713)$, followed by double-teaming group defence with a mean of $(\overline{\mathbf{x}}=7.903)$. Participants in double-teaming group playing midfield had the least mean score of $(\overline{\mathbf{x}}=7.846)$. This shows that attacking players are better than defence and midfield players.in scoring precision.

In set pieces group, defence players had the highest mean of $(\overline{\mathbf{x}}=8.553)$, followed by the midfield players with a mean value of $(\overline{\mathbf{x}}=8.181)$. While the attacking players had the least mean score of $(\overline{\mathbf{x}}=6.963)$. This showed that participants in set pieces group playing defence are better in scoring precision than the midfield while the attacking players had lowest in scoring precision.

In the control group however, participants playing defence had the highest mean of ( $\overline{\mathbf{x}}=2.893)$, followed by forward players with a mean value of $(\overline{\mathbf{x}}=2.786)$. Defence players had the least mean score of $(\overline{\mathbf{x}}=2.329)$. This shows that in control group defence players are better in scoring precision. Overall comparison shows that participants playing forward in double-teaming group were the best in scoring precision followed by those playing defence in set pieces. Therefore, there was no significant interaction effect of Treatment and Playing Position on Scoring Precision of University of Ibadan football players. $\left(\mathrm{F}=.488, \mathrm{p}>.05, \eta^{2}=.281\right)$. Thus, the null hypothesis is accepted. The eta value of .281 showed that $28.1 \%$ of the variance in the participant's score was accounted for by the intervention.

Hypothesis five: There will be no significant interaction effect of Treatment and Playing Experience on Scoring Precision of University of Ibadan football players.

Table 8: Estimated marginal means of Treatment and

Playing Experience on Scoring Precision of University of Ibadan football players

\begin{tabular}{|l|l|c|c|c|c|}
\hline \multirow{2}{*}{ Treatment } & \multirow{2}{*}{ Playing Experience } & \multirow{2}{*}{$\mathbf{x}$} & Std. & \multicolumn{2}{|c|}{$\mathbf{9 5 \% \text { Confidence Interval }}$} \\
\cline { 5 - 6 } & & & Error & Lower Bound & Upper Bound \\
\hline Double-teaming & Short & 8.101 & .576 & 6.621 & 9.581 \\
& Long & 7.953 & .682 & 6.201 & 9.706 \\
\hline Set pieces & Short & 7.878 & .465 & 6.684 & 9.072 \\
& Long & 7.603 & .681 & 5.852 & 9.354 \\
\hline Control & Short & 2.862 & .533 & 1.492 & 4.232 \\
& Long & 2.323 & .607 & .763 & 3.883 \\
\hline
\end{tabular}

Table 8 shows the estimated marginal means of Treatment and Playing Experience on Scoring Precision of University of Ibadan football players. Although, the interaction of treatment and playing experience was not significant in enhancing scoring precision, however, participants who are in double-teaming group with short playing experience had the highest mean of $(\overline{\mathbf{x}}=8.101)$, followed by participants in double-teaming group with long playing experience with a mean value of $(\overline{\mathbf{x}}=7.953)$. Participants in set pieces group with short playing experience had mean score of $(\overline{\mathbf{x}}=7.878)$ while participants with 
long playing experience had mean score of $(\overline{\mathbf{x}}=7.603)$. In the control group, participants with short playing experience are better with mean score of $(\overline{\mathbf{x}}=7.603)$ than players with short playing experience group with mean score of $(\overline{\mathbf{x}}=2.862)$ are better than long playing experience who has score of $(\overline{\mathbf{x}}=2.323)$ Overall comparison shows that participants in the double-teaming group with short playing experience were the best in scoring precision followed by those in the set pieces group with short playing experience while participants in the control group with long playing experience are the least in scoring precision. As indicated in Table 7 above, there was no significant interaction effect of Treatment and Playing Experience on Scoring Precision of University of Ibadan football players. ( $F=$ $\left..353, p>.05, \eta^{2}=.124\right)$. Thus, the null hypothesis is accepted. The eta value of .124 shows that $12.4 \%$ of the variance in the participant's score was accounted for by the intervention.

Hypothesis six: There will be no significant interaction effect of Playing Position and Playing Experience of University of Ibadan football players.

Table 9: Estimated marginal means of Playing Position and

Playing Experience on Scoring Precision of University of Ibadan football players

\begin{tabular}{|c|c|c|c|c|c|}
\hline \multirow{2}{*}{ Playing Position } & \multirow{2}{*}{ Playing Experience } & \multirow[t]{2}{*}{$\overline{\mathbf{x}}$} & \multirow{2}{*}{$\begin{array}{l}\text { Std. } \\
\text { Error }\end{array}$} & \multicolumn{2}{|c|}{ 95\% Confidence Interval } \\
\hline & & & & Lower Bound & Upper Bound \\
\hline \multirow[t]{2}{*}{ Forward } & Short & 6.263 & .462 & 5.076 & 7.450 \\
\hline & Long & 6.636 & .980 & 4.117 & 9.156 \\
\hline \multirow[t]{2}{*}{ Midfield } & Short & 6.233 & .521 & 4.894 & 7.571 \\
\hline & Long & 6.381 & .452 & 5.219 & 7.543 \\
\hline \multirow[t]{2}{*}{ Defence } & Short & 6.346 & .537 & 4.965 & 7.727 \\
\hline & Long & 4.990 & .678 & 3.248 & 6.731 \\
\hline
\end{tabular}

Table 9 shows the estimated marginal means of playing position and playing experience on scoring precision of the players. Although, the interaction of playing position and playing experience was not significant in enhancing scoring precision, however, participants who are in the forward as playing position with long playing experience had high mean of $(\overline{\mathbf{x}}=6.636)$, followed by participants playing in the midfield but with long playing experience having a mean of $(\overline{\mathbf{x}}=6.381)$. Participants with long playing experience playing from the midfield had the high mean score of $(\overline{\mathbf{x}}=6.381)$ while participants with short playing experience and playing in the midfield had low mean score of $(\overline{\mathbf{x}}=6.233)$. Participants with long playing experience and playing forward had higher mean score of $(\overline{\mathbf{x}}=6.636)$ while participants with short playing experience and playing forward had mean score of $(\overline{\mathbf{x}}=6.263)$. This showed that participants with long playing experience playing in the attack are better in scoring precision than the participants with short playing experience playing in the defence. Participants with long playing experience playing in the midfield are better than the participants with short playing experience playing in the midfield in scoring precision. Similarly, the participants with long playing experience playing forward are better than the participants with short playing experience playing forward. Overall comparison shows that participants with long playing experience playing forward were the best in scoring precision followed by 
those with long playing experience playing in the midfield while participants with long playing experience and playing in the defence are the least in scoring precision. Result also indicated that there was no significant interaction effect of Playing Position and Playing Experience on Scoring Precision of University of Ibadan football players $(\mathrm{F}=.310$, $p>.05, \eta 2=.110$ ). Thus, the null hypothesis is accepted. The eta value of .110 showed that $11.0 \%$ of the variance in the participant's score was accounted for by the intervention.

Hypothesis Seven: There will be no significant interaction effect of Treatment, Playing Position and Playing Experience on Scoring Precision of University of Ibadan football players.

Result in Table 4.11 below showed that there was no significant interaction effect of Treatment, Playing Position and Playing Experience on Scoring Precision of University of Ibadan football players ( $\mathrm{F}=.025, \mathrm{p}>.05, \mathrm{\eta} 2=.005)$. Thus, the null hypothesis is accepted. The eta value of .005 showed that $5 \%$ of the variance in the participant's score was accounted for by the intervention.

Table 10: Estimated marginal means of Treatment, Playing Position and Playing Experience on Scoring Precision of University of Ibadan football players

\begin{tabular}{|c|c|c|c|c|c|c|}
\hline \multirow{2}{*}{ Treatment } & \multirow{2}{*}{$\begin{array}{l}\text { Playing } \\
\text { Position }\end{array}$} & \multirow{2}{*}{$\begin{array}{l}\text { Playing } \\
\text { Experience }\end{array}$} & \multirow{2}{*}{$\overline{\mathbf{x}}$} & \multirow{2}{*}{$\begin{array}{l}\text { Std. } \\
\text { Error }\end{array}$} & \multicolumn{2}{|c|}{ 95\% Confidence Interval } \\
\hline & & & & & Lower Bound & Upper Bound \\
\hline \multirow{6}{*}{$\begin{array}{l}\text { Double- } \\
\text { Teaming }\end{array}$} & Defence & Short & 7.896 & 1.064 & 5.161 & 10.631 \\
\hline & & Long & 7.910 & 1.010 & 5.314 & 10.506 \\
\hline & Midfield & Short & 7.696 & 1.064 & 4.961 & 10.431 \\
\hline & & Long & 7.997 & .774 & 6.006 & 9.987 \\
\hline & Forward & Short & 8.713 & .684 & 6.945 & 10.472 \\
\hline & & Long & - & - & - & - \\
\hline \multirow{6}{*}{$\begin{array}{l}\text { Set } \\
\text { Pieces }\end{array}$} & Defence & Short & 8.553 & .681 & 6.802 & 10.304 \\
\hline & & Long & - & - & - & - \\
\hline & Midfield & Short & 7.793 & .718 & 5.946 & 9.639 \\
\hline & & Long & 8.569 & 1.020 & 5.946 & 11.192 \\
\hline & Forward & Short & 7.290 & .958 & 4.827 & 9.752 \\
\hline & & Long & 6.636 & .980 & 4.117 & 9.156 \\
\hline \multirow[t]{6}{*}{ Control } & Defence & Short & 2.590 & .958 & .127 & 5.052 \\
\hline & & Long & 2.069 & 1.020 & -.554 & 4.692 \\
\hline & Midfield & Short & 3.210 & 1.010 & .614 & 5.806 \\
\hline & & Long & 2.576 & .679 & .832 & 4.320 \\
\hline & Forward & Short & 2.786 & .708 & .965 & 4.608 \\
\hline & & Long & - & - & - & - \\
\hline
\end{tabular}

Table 10 shows the estimated marginal means of treatment, playing position and playing experience on scoring precision of the players. Although, the interaction effect of the treatment (playing position and playing experience) was not significant enough to enhance scoring precision. However, participants who are in double-teaming group playing forward had the highest mean effect of $(\overline{\mathbf{x}}=7.910$. Participants in the set pieces group playing in the midfield with long playing experience had a high marginal mean of 
$(\overline{\mathbf{x}}=8.569)$ while participants in set pieces group playing in the defence with long playing experience had nil marginal mean.

Table 11: ANCOVA showing the main and interaction effect of Treatment, Playing position and Playing Experience on Scoring Precision of University of Ibadan Football Players

\begin{tabular}{|l|c|c|c|c|c|c|}
\hline Source & $\begin{array}{c}\text { Sum of } \\
\text { Squares }\end{array}$ & DF & $\begin{array}{c}\text { Mean } \\
\text { Square }\end{array}$ & F & Sig. & $\begin{array}{c}\text { Eta. } \\
\text { Sq }\end{array}$ \\
\hline Corrected Model & 142.650 & 15 & 9.510 & 10.363 & .009 & .969 \\
Intercept & 7.288 & 1 & 7.288 & 7.942 & .037 & .614 \\
Pretest & 0.397 & 1 & 0.397 & 0.432 & .540 & .080 \\
\hline Main effect & & & & & & \\
Treatment & 119.515 & 2 & 59.757 & 65.120 & .000 & .963 \\
Playing Position & 0.569 & 2 & 0.285 & 0.310 & .746 & .110 \\
Playing Experience & 0.126 & 1 & 0.126 & 0.138 & .726 & .027 \\
\hline 2-way Interactions & & & & & & \\
Treatment x P.P & 1.793 & 4 & 0.448 & 0.488 & .746 & .281 \\
Treatment x P.E & 0.649 & 2 & 0.324 & 0.353 & .718 & .124 \\
P.P X P.E & 0.569 & 2 & 0.285 & 0.310 & .746 & .110 \\
\hline 3-way interactions & & & & & & \\
Treatment X P.P x P.E & $2.286 \mathrm{E}-02$ & 1 & $2.286 \mathrm{E}-02$ & 0.025 & .881 & .005 \\
Error & 4.588 & 5 & 0.918 & & & \\
Total & 960.690 & 21 & & & & \\
Corrected Total & 147.238 & 20 & & & & \\
\hline
\end{tabular}

R Squared $=.969$ (Adjusted R Squared $=.875)$

Table 11 shows the main and interaction effects of treatment, playing position and playing experience on scoring precision of University of Ibadan football players. It is also observed that there was a variance of 87.5 percent accounted for by the independent variables combined together.

This study is in line with Thorndike's theory of learning referred to as 'connectionism'. It is a learning theory based on the concept of bonds formed between stimulus and response. That is natural connections between situations ( $S$ ) and responses (R) are formed and strengthened. The stimulus affects the organism which responds to it. Thus S-R bonds are formed which are considered as physical conditions. This theory of learning is related to conditioning in that it utilises the concept of association of connection. It emphasizes that the behavior begins with conditioned reflexes and natural responses and new behaviours result from the acquisition of new bonds through experience.

\section{Conclusion}

Based on the findings of this study, it was concluded that the treatment was effective on scoring precision among football players. However, it was also concluded that doubleteaming was better on scoring precision than set pieces. There was no significant main effect of playing position on scoring precision. However, players with long playing 
experience playing in the attack are better in scoring precision than the players with short playing experience playing in the defence. Participants with long playing experience playing in the midfield are better than the participants with short playing experience playing in the midfield on scoring precision. Similarly, the participants with long playing experience playing forward are better than the participants with short playing experience playing forward: this is perhaps due to experience and consistency. Overall comparison shows that participants with long playing experience playing forward were the best in scoring precision followed by those with long playing experience playing in the midfield while participants with long playing experience and playing in the defence are the least in scoring precision.

\subsection{Significance of the Study and Contributions to Knowledge}

The study provided empirical data on the effect of set pieces and double-teaming on scoring precision of football players. The outcome of the study may be useful to football coaches who may wish to improve on the scoring precision of their players. The study might also help improve the scoring prowess of the University of Ibadan Football players. It might put the name of the University of Ibadan on a higher pedestal than before in football. It may also generate more revenue for the Sports Council and the University of Ibadan through winning of laurels including the Nigeria University Games Association meet, Oyo State Tertiary Institution Games, Ibadan Football Association League, the University League games and so on. It may also serve as reference material to researchers who may be interested in studying allied areas in the future. It was established through the outcome of this study that this study is in line with the work of Hughes (2012) which states that more goals can be scored from set pieces and double-teaming or immediately from regained possession following a clearance from set plays and double-teaming. It is very important to learn to convert the chances from set plays and double-teaming into goals through scoring precision. This study established that set pieces training was an effective programme that brought about improvement in scoring precision.

\subsection{Recommendations}

Based on the findings of this study, the following cogent conclusions were made:

The findings of this study revealed the need for football coaches to be educated on the benefits of usage of double-teaming and set pieces during training to improve scoring precision during games. Coaches should concentrate on simplified and better methods of training double-teaming and set pieces.

It was therefore recommended that:

1. Football Coaches should make use of set-pieces and double-teaming more during play as against the usual against the run of play tactical play.

2. Football Coaches should endeavour to use double-teaming more among midfielders. 
3. Since this study revealed that double-teaming was more effective that set-pieces, football coaches should train and use double-teaming tactical play more often during games.

4. Coaches should take note of the importance of using players with high speed when executing double-teeming during games because it is crucial to its usage.

\section{Conflict of Interest Statement}

There is no conflict of interest whatsoever in this article.

\section{About the Author}

Festus A. Adegoju graduated with BSc. (Hons) Zoology and proceeded to study Post Graduate Diploma in Education (PGDE) in Teacher Education (Biological Sciences). He further reformed his discipline because of his thirst for Sport Science and football coaching to study Human Kinetics and Health Education where he bagged B.Ed. Hons. (First Class). He progressed to study Masters of Exercise Physiology (Sport Medicine) in the same department where he graduated M.Ed. with Distinction. This author holds a Confederation of African Football "A" Coaching License. He has coached a lot of clubs including the University of Ibadan Football Team, Nigeria. He is the current Chairman of the Nigeria Football Coaches Association (Oyo State Chapter), Nigeria. He has authored several articles in various journals. He is presently a Doctoral Research Scholar in the Exercise Physiology Unit of the Department of Human Kinetics and Sport Education, Faculty of Education, University of Ibadan, Ibadan, Nigeria.

\section{References}

Adegoju, F. A. and Abon, J. K. (2020). Effects of Double-Teaming and Three-Man Weave Training on Goal-Scoring Accuracy among Players of Federal University of Agriculture Football Team, Abeokuta, Ogun State, Nigeria. British Journal of Education. Vol. 9, Issue 1, pp.68-85, 2020.

Akinbo, S. Salau, M. Odebiyi, D. and Ibeabuchi, N. (2007). Video Analysis of Musculoskeletal Injuries in Nigerian and English Professional Soccer Leagues: A Comparative. Retrieved from https://www.ajol.info/index.php/njhbs/article/view/11650

Brad, D. (2014). Home Articles Blog O-Line: The double team. My cart. Brad DeHaven Blog 0 Comment. Retrieved July 21, 2014.

Dukić, B. (2000). Technical elements in football: Beograd: Borivoj Dukić.

Football Tips (2012). Free daily football tips (95\%) wins. Sports Nigeria. Nairaland. Hughes, M. (2012). The Set Pieces: football and conflict, the story of FC Pristina and the Kosovo War. From London Amateur to MLS professional. 
Maric, K. (2013). Relationship between basic and specific motor abilities and player quality of young players. Differences in learning styles: Social and behavioral sciences, 478-480.

Nićin, D. (2000). Antropomotorics (theory). Nico sad: Faculty of Physical Culture.

Owoeye, O. Akinbo, S. Olawale O. Tella, B. and Ibeabuchi, N. (2013). Injury prevention in football: Knowledge and behaviour of players and availability of medical care in a Nigerian youth football league SAJSM; 25 (3):77-8.

Soccer Guide, (2010). Soccer drills and practice plans. Soccer-training-guide.com. Retrieved 2010-08-22.

Stojiljković, S. (2003). Base plate of anthropomotor launchis student cultural center. Nigerian Journal of Health and Biomedical Sciences, 6(2); 85-9. 

be applied to their work. Under the terms of this license, no permission is required from the author(s) or publisher for members of the community to copy, distribute, transmit or adapt the article content, providing a proper, prominent and unambiguous attribution to the authors in a manner that makes clear that the materials are being reused under permission of a Creative Commons License. Views, opinions and conclusions expressed in this research article are views, opinions and conclusions of the author(s). Open Access Publishing Group and European Journal of Physical Education and Sport Science shall not be responsible or answerable for any loss, damage or liability caused in relation to/arising out of conflict of interests, copyright violations and inappropriate or inaccurate use of any kind content related or integrated on the research work. All the published works are meeting the Open Access Publishing requirements and can be freely accessed, shared, modified, distributed and used in educational, commercial and non-commercial purposes under a Creative Commons attribution 4.0 International License (CC BY 4.0). 